\title{
Periodontitis and Rheumatoid arthritis - A Review
}

\author{
Nalayini Ellamurugan, ${ }^{1}$ Karthikeyan. I ${ }^{2}$ \\ ${ }^{1}$ BDS, Saveetha Dental college/ Saveetha University, India \\ ${ }^{2}$ Department Of Periodontics, Saveetha Dental college/ Saveetha University, India
}

\begin{abstract}
The periodontal disease is an inflammatory condition of the supporting structres of the teeth. The presence of rheumatoid arthritis or other systemic inflammatory disease may increase the severity of the periodontal disease. The studies published in the past reveals that the oral bacterial infections and inflammation seemed to be linked directly to the etiopathogenesis of rheumatoid arthritis. There are findings support the impact of periodontal pathogens, such as Porpyromonas gingivalis on citrullination, and the association of periodontitis in rheumatoid arthritis patients with serospecificity toward rheumatoid factor and the anti-cyclic citrullinated peptide antibody ${ }^{l}$.In this review the common etiology, pathogenesis and immunogenetics of two chronic inflammatory conditions are discussed.
\end{abstract}

Keywords: Chronic inflammatory disease, Periodontitis, Rheumatoid arthritis,

\section{Introduction}

Oral cavity is the window of overall health and body system, as from the oral diseases many systemic diseases can be diagnosed. Periodontitis, a leading cause of tooth loss is a chronic destructive inflammatory disease of the supporting tissues of the teeth which is caused by a gram negative anaerobic bacterium. $10-15 \%$ of adult population develops periodontal disease through gingivitis an inflammation of marginal periodontium. ${ }^{1}$ Rheumatoid arthritis is a chronic inflammatory autoimmune disease that leads to significant synovial inflammation and its tissue degeneration. Both the diseases, manifest as a result of imbalance between proinflammatory and anti-inflammatory cytokines ${ }^{2}$, cause local destruction of connective tissue and bone as a consequence of persistent inflammation There are clinical evidence that shows by eliminating periodontal infection by scaling and root planning of the teeth of patients with RA, the patients show decrease in joint pain. Periodontitis which is characterized by pocket formation, loss of attachment, mobility of the tooth and furcation appears to be a more specific periodontal pathogens present in the subgingival biofilm. Both the amount and the microorganisms and the resistance factors of the hos tare crucial for the initiation and progression of the periodontal destruction ${ }^{3}$.PD is to be understood as an opportunistic infection ${ }^{4}$.It results in tissue injury or provokes excessive, autodestructive inflammatory responses ${ }^{1} \mathrm{Gram}$, depending on the pathogenicity of the agents or the performance of the immune defense. negative anaerobic bacteria, which form a bacterial plaque biofilm on the tooth surface initiate this tissue destroying process. ${ }^{5}$

Porphyromonas gingivalis, Prevotella intermedia,Tannerella forsythia and Aggregatibacter actinomycetem-comitans are the most commonest bacteria which have been identified as periodontal pathogens and are linked to several forms of PD. ${ }^{6}$ In the periodontal pocket ,there exists a condition in which periodontopathic bacteria form a film-like colony by adherence and aggregation. ${ }^{7}$ Few hours later ,resident microorganisms-most of which are mostly Gram positive stick to the membranaceous layer of the smooth surface of the teeth, which settles within few minutes up to a few hours through mechanical tooth cleaning. By means of fimbriae, pili Gram negative bacteria can attach to those microorganisms. Bacteria are protected from immunologic defense mechanisms of the hosts as well as from antibiotic agents due to the complexity and subgingival location. ${ }^{8}$ Continuous stimulation by bacteria inflicts injury within the gingiva, destroys osteoclasts in the tissue, so that the PD can progress. ${ }^{9}$

\section{Materials and methods}

The literature search was done using Pubmed search by using the key words "Periodontitis and Rheumatoid Arthritis"

\section{Similarities between Periodontitis and Rheumatoid Arthritis}

\subsection{Natural History}

\subsubsection{Periodontal disease:}

The periodontal diseases are resulting from the induction of host inflammatory responses to the subgingival biofilm. Gingivitis which is characterized by edematous, erythematous gum which bleeds on probing confined to supragingival connective tissue and it is relatively nonspecific response to a nonspecific accumulation of dental plaque. ${ }^{10}$ 
Natural history studies of periodontal disease in humans indicate the presence of three distinct subpopulations: ${ }^{11}$ 1) No progression of periodontal disease, in which around $10 \%$ of the population manifest very little or no disease which is of no particular consequence to the dentition;

2) Moderate progression, affecting around $80 \%$ of the population and representing a very slowly progressing form of disease that generally can be easily managed via routine therapies; and

3) Rapid progression, affecting approximately $8 \%$ of individuals whereby extensive periodontal destruction occurs which can be very difficult to control.

\subsubsection{Rheumatoid Arthritis:}

At least three types of disease manifestation can also be observed in RA populations:

1) Self-limited: in these cases individuals originally presenting for RA have no evidence of disease 3 to 5 years Later ${ }^{12}$;

2) Easily controlled: the disease is relatively easily controlled with only nonsteroidal anti-inflammatory drugs (NSAIDs); ${ }^{13}$

3) Progressive: these patients generally require second-line drugs, which often still do not fully control the disease ${ }^{14}, 15$

\subsection{Etiology}

\subsubsection{Periodontal diseases:}

All forms of periodontal diseases are associated with chronic inflammation (accumulation of B and T lymphocytes, monocytes and neutrophils, tissue edema, endothelial cell proliferation and matrix degeneration), resulting in destruction of the periodontal ligament and the bone. If left untreated significant tissue damage occurs and the affected teeth can become loose and may be lost if the disease continues to be active.

Although bacteria are necessary for disease initiation, they are not sufficient to cause disease progression unless there is an associated inflammatory response within a susceptible host. ${ }^{16}$

\subsubsection{Rheumatoid Arthritis}

The recent studies reveal, in rheumatoid arthritis many arthritogenic stimuli activate inflammatory responses in immunogenetically susceptible host. The current information based on these reveals that no particular pathogen is identified as the causative organism for the RA. Thus, studies have focused on exogenous infectious agents, endogenous substances, such as connective tissue proteins (e.g., collagens and proteoglycans), and altered immunoglobulin as the causative candidates. Nonetheless, RA is still not largely recognized as a disease resulting solely from bacterial challenge. On the other hand, technological and conceptual advances have permitted the identification of bacteria or groups of bacteria associated with specific periodontal diseases. ${ }^{17}$ It is important to recognize that, based on current information, we do not propose that periodontal pathogens cause, or are associated with, RA.

\subsection{Immunogenetics}

\subsubsection{Periodontitis:}

Many of these interindividual variables relate to severity of periodontal destruction, and other inflammatory responses are attributed partly to the amount and type of cytokines that individuals produce. ${ }^{18}$ While the HLA-DR phenotype is not particularly strong for periodontitis, there is a report indicating that it is an important component of the genetic susceptibility to some forms of this disease. ${ }^{19}$ In addition, polymorphisms in the interleukin-1b (IL-1b) gene cluster have been shown to have a significant correlation with some forms of periodontitis in certain populations. ${ }^{20}$

\subsubsection{Rheumatoid Arthritis}

For RA, the strongest genetic associations are found within the HLA genes. ${ }^{20}$ The HLA genes and gender constitute about $30 \%$ of the genetic risk in RA, while other genetic factors such as cytokine genes, germline genes, and T-cell receptors also account for some of the genetic predisposition to RA. ${ }^{21}$ Using DNA sequencing and molecular-based typing, it has been demonstrated that the disease-conferring portion of the $\mathrm{D}$ region is confined to a short sequence within the third hypervariable region of HLA-DRB1 gene which includes the amino acid positions 67 through $74 .^{22,23}$

\subsection{Pathogenesis}

Both the amount and virulence of the microorganisms and the resistance factors of the host (risk factors and immune status) are crucial for the initiation and progression of the periodontal destruction ${ }^{24}$.PD is to be understood as an opportunistic infection ${ }^{25}$. 
In particular, Gram-negative anaerobic bacteria, which form a bacterial plaque biofilm on the tooth surface, initiate this tissue-destroying process ${ }^{26}$. There are other factors at the molecular level responsible for the pathogenesis such as the RANK with macrophage colony stimulating factor regulating osteoclast formation and activation ${ }^{27,28}$. Among a complex and still largely unknown microflora, about 20 bacteria species, which live in the subgingival environment, have been identifi ed as periodontal pathogens and are linked to several forms of PD. The best analyzed of these bacteria are Porphyromonas gingivalis, Prevotella intermedia, Tannerella forsythia, and Aggregati bacter actinomycetem-comitans. ${ }^{29}$

\subsection{Effector mechanisms of tissue destruction \\ 3.5.1 Periodontitis}

There is almost universal acceptance that a variety of cytokines and matrix metalloproteinases (MMPs) are upregulated and intimately involved in the pathogenesis of both periodontitis and RA; many of these effector molecules appear to be common to both diseases.

Periodontitis has very similar cytokine profiles to $\mathrm{RA},{ }^{24,25}$ consisting of persistent high levels of proinflammatory cytokines, including IL-1b and tumour necrosis factor-alpha (TNF-a), and low levels of cytokines which suppress the immunoinflammatory response such as IL-10 and transforming growth factor-b (TGF-b). These cytokines, together with low levels of tissue inhibitors of metalloproteinase (TIMPs) and high levels of MMPs and prostaglandin E2 (PGE2), are associated with the active stages of periodontitis.

Together, these soluble mediators of inflammation are able to induce degradation of collagen and proteoglycans either through direct or indirect means. Production of the arachidonic acid metabolite PGE2 as well as the release of neutrophil-associated enzymes, such as neutrophil elastase and b-glucuronidase, together with the secretion of matrix metalloproteinase by macrophages and synoviocytes, all contributes significantly to the pathogenesis of RA.

\subsection{Osteoclast activation and vascular damage -A common pathway in Periodontitis and Rheumatoid Arthritis}

The cell surface Tumour necrosis factor (TNF)-like molecule, receptor activator of nuclear kappa ligand (RANKL) and its receptor, RANK with macrophage colony stimulating factor have been shown to be key factors regulating osteoclast formation and activation ${ }^{27,28}$. It has been shown that when RANKL binds to RANK on the surface of osteoclast precursors, these cells differentiate to form mature osteoclasts. The soluble TNF "receptor-like" molecule, osteopretogerin (OPG), is a natural inhibitor of RANKL. ${ }^{30}$ OPG binds to RANKL and prevents its ligation to RANK.

OPG has been reported to be required for endothelial cell survival and growth. ${ }^{31}$ In response to pro inflammatory cytokines TNF-a and IL-1b, OPG mRNA expression was dramatically enhanced, resulting in secretion of newly synthesized OPG and a reduction in cell-associated OPG.

\subsection{Treatment}

Currently, the mainstream "first-line" modes of treatment for RA remain the NSAIDs such as aspirin, naproxen, diclofenac, and ibuprofen. Their mechanism of action through the inhibition of cyclooxygenase (COX) synthesis produces both analgesic and antipyretic properties. While these medications are effective in reducing the pain symptoms in RA, they do not significantly alter its course. ${ }^{32}$ The use of NSAIDs for management of periodontal disease has been studied over the past 20 years. ${ }^{33-35}$

In contrast to the NSAIDS, which do not significantly alter the course of RA, a newer family of medications designated disease-modifying anti-rheumatic drugs (DMARDs) has been developed. To be classified as a DMARD, the medication must demonstrate an ability to change the course of RA for at least 1 year as evidenced by sustained improvement in function, decreased synovitis, and prevention of further joint damage. ${ }^{36}$ Examples of these medications include parenteral gold salts, methotrexate, sulfasalazine, hydroxychloroquine (antimalarial drug), penicillamine, azathioprine, and leflunomide. A major drawback in the use of DMARDs is their considerable toxicity. ${ }^{37,38}$

The use of DMARDs for the management of periodontitis has been restricted largely due to the toxicity issues. Another emerging area of potential for host modulation in periodontitis and rheumatoid arthritis is control of the MMPs that are important mediators of connective tissue breakdown in both hard and soft tissues. In this regard, tetracycline and various chemical analogues have been found to inhibit MMP activity by a mechanism that is independent of their antimicrobial property. ${ }^{39,40}$

\section{Conclusion}

Emerging evidence suggests a strong relationship between the extent and severity of periodontal disease and rheumatoid arthritis. The existence of an inflammatory systemic disease may promote PD in both its emergence and progress. Oral hygiene and smoking represent environmental factors influencing the risk for the 
development of RA.Inhibition of common mediators and effector molecules such as MMPs can reduce the severity of both of these diseases.

\section{References}

[1]. The association between rheumatoid arthritis and periodontal disease- Jacqueline Detert,Nicole Piscon,Gerd R Burmester and Frank Buttgereit.

[2]. Periodontitis and Rheumatoid Arteritis' Review -P.M.Bartold,R.I.Marsall,D.r. Haynes

[3]. DetertJ,Pischon N,Burmester GR Buttgerit F:Patogenesis of periodontitis in rheumatic diseases.Z Rheumatol 2010,6:109-112

[4]. Lovegrove JM:Dental plaque revisited: bacteria associated wit periodontal disease J N Z Soc Periodontal 2004,(87):7-21

[5]. Socransky SS, haffajee AD dental biofilms: difficult therapeutic targets. Periodontal 2000 2002,28:12-55review

[6]. Moore WE,Moore LV:Te bacteria of periodontal diseases. Periodontal 2000 2000,5;66-77

[7]. Kolenbrander PE,London J:Adhere today, here tomorrow: oral bacterial adherence.J Bacteriol 1993,175:3247-3252

[8]. Whittaker CJ,Klier CM,Kolenbrander PE:mecanisms of adhesion by oral bacteria.Annu Rev Microbial 1996,50:513-552

[9]. Wang PL,Ohura K;Porphyromonas gingivalis lipopolysaccharide signaling in gingival fibroblasts-CD14 and Toll like Receptors.Crit Rev Oral Biol med 2002,13:132-142

[10]. Page RC, Offenbacher S, Schroeder HE, Seymour GJ, Kornman KS. Advances in the pathogenesis of periodontitis: Summary of developments, clinical implications and future directions. Periodontal 2000 1997;14:216-248.

[11]. Hirschfeld L, Wasserman B. A long-term survey of tooth loss in 600 treated periodontal patients. J Periodontol 1978;49:225-237.

[12]. O'Sullivan JB, Cathcart ES. The prevalence of rheumatoid arthritis. Follow-up evaluation of the effect of criteria on rates in Sudbury, Massachusetts. Ann Intern Med 1972;76:573-577.

[13]. Pincus T, Marcum SB, Callahan LF. Long-term drug therapy for rheumatoid arthritis in seven rheumatology private practices: II. Second line drugs and prednisone. J Rheumatol 1992;19:1885-1894.

[14]. Pincus T, Marcum SB, Callahan LF, et al. Long-term drug therapy for rheumatoid arthritis in seven rheumatology private practices. I. Non-steroidal anti-inflammator drugs. J Rheumatol 1992;19:1874- 1884.

[15]. Wolfe F, Hawley DJ, Cathey MA. Termination of slow acting antirheumatic therapy in rhematoid arthritis: A 14-year prospective evaluation of 1017 consecutiv starts. J Rheumatol 1990;17:994-1002.

[16]. Page RC, Offenbacher S, Schroeder HE, Seymour GJ, Kornman KS. Advances in the pathogenesis of periodontitis: Summary of developments, clinical implications and future directions. Periodontal 2000 1997; 14:216-248.

[17]. Zambon JJ. Periodontal diseases: Microbial factors. Ann Periodontal 1996;1:879-925.

[18]. Salvi GE, Brown CE, Fujihashi K, et al. Inflammatory mediators of the terminal dentition in adult and early onset periodontitis. J Periodontal Res 1998;33:212-225.

[19]. Michalowicz BS, Diehl SR, Gunsolley JC, et al. Evidence of a substantial genetic basis for adult periodontitis. J Periodontol 2000;71:1699-1707.

[20]. Kornman KS, Crane A, Wang H-Y, et al. The interleukin-1 genotype as a severity factor in adult periodontal disease. J Clin 77

[21]. Weyand CM. New insights into the pathogenesis of rheumatoid arthritis. Rheumatology 2000;39(Suppl. 1): 3-8.

[22]. Kurosaka M, Ziff M. Immunoelectron microscopic study of the distribution of T cell subsets in rheumatoid synovium. J Exp Med $1983 ; 158: 1191-1210$.

[23]. Nepom GT, Nepom BS. Prediction of susceptibility to rheumatoid arthritis by human leukocyte antigen genotyping. Rheum Dis Clin Am 1992;18: 785-792

[24]. Detert J, Pischon N, Burmester GR, Buttgereit F: Pathogenesis of periodontitis in rheumatic diseases. Z Rheumatol 2010, 69:109112.

[25]. Lovegrove JM: Dental plaque revisited: bacteria associated with periodontal disease. J N Z Soc Periodontol 2004, (87):7-21.

[26]. Socransky SS, Haff ajee AD. Dental biofi lms: diffi cult therapeutic targets. Periodontol 2000 2002, 28:12-55. Review.

[27]. Yasuda H, Shima N, Nakagawa N, et al. Osteoclast differentiation factor is a ligand for osteoprotegerin/osteoclastogenesisinhibitory factor and is identical to TRANCE/RANKL. Proc Natl Acad Sci USA 1998;95: 3597-3602. Periodontitis and Rheumatoid Arthritis Volume 76 • Number 11 (Suppl.) 2072

[28]. Lacey DL, Timms E, Tan HL, et al. Osteoprotegerin ligand is a cytokine that regulates osteoclast differentiation and activation. Cell 1998;93:165-176.

[29]. Moore WE, Moore LV: The bacteria of periodontal diseases. Periodontol 20002000, 5:66-77.

[30]. Simonet WS, Lacey DL, Dunstan CR, et al. Osteoprotegerin: A novel secreted protein involved in the regulation of bone density. Cell 1997;89:309-319.

[31]. Malyankar UM, Scatena M, Suchland KL, Yun TJ, Clark EA, Giachelli CM. Osteoprotegerin is an avb3- induced, NF-kBdependent survival factor for endothelial cells. J Biol Chem 2000;275:20959-20962.

[32]. Lipsky PE. Rheumatoid arthritis. In: Wilson JD, Braunwald E, Isselbacher KJ, et al., eds. Harrison's Principles of Internal Medicine, 12th ed. New York: McGraw-Hill; 1991:1437-1443.

[33]. Feldman RS, Szeto B, Chauncey HH, Goldhaber P. Non-steroidal anti-inflammatory drugs in the reduction of human alveolar bone loss. J Clin Periodontol 1983;10:131-136.

[34]. Jeffcoat MK, Page R, Reddy M, et al. Use of digital radiography to demonstrate the potential of naproxen as an adjunct in the treatment of rapidly progressive periodontitis. J Periodontal Res 1991;26:415-421.

[35]. Paquette DW, Williams RC. Modulation of host inflammatory mediators as a treatment strategy for periodontal diseases. Periodontol 2000 2000;24:239-252.

[36]. Paget S. Treatment. In: Klippel J, ed. Primer on the Rheumatic Diseases. Atlanta: Arthritis Foundation;1997:168-174.

[37]. American College of Rheumatology Ad Hoc Committee on Clinical Guidelines. Guidelines for monitoring drug therapy in the management of rheumatoid arthritis. Arthritis Rheum 1996;39:713-722.

[38]. Golub LM, Lee HM, Lehrer G, et al. Minocycline reduces gingival collagenolytic activity during diabetes: Preliminary observations and a proposed new mechanism of action. J Periodontal Res 1983;18:516-526.

[39]. Snyderman R, McCarty GA. Analogous mechanisms of tissue destruction in rheumatoid arthritis and periodontal disease. In: Genco RJ, Mergenhagen SE, eds. Host-Parasite Interaction in Periodontal Diseases. Washington, DC: American Society for Microbiology; 1982:354-362.

[40]. Arend WP, Dayer JM. Cytokines and cytokine inhibitors or antagonists in rheumatoid arthritis. Arthritis Rheum 1990;33:305-315. 